Т. В. Нескородєва

Донецький національний університет імені Василя Стуса, Вінниця, Україна

\title{
ПОСТАНОВКА ЗАДАЧ АВТОМАТИЗОВАНОГО АНАЛІЗУ ДАНИХ У ПІДСИСТЕМІ АУДИТУ ПЕРЕДУМОВИ ІНФОРМАЦІЙНІЙ ТЕХНОЛОГІЇ СИСТЕМИ ПІДТРИМКИ ПРИЙНЯТТЯ РІШЕНЬ
}

\begin{abstract}
Мета статті. Виконати постановку задач аудиту автоматизованого аналізу даних в підсистемі аудиту передумови Положень (стандартів) бухгалтерського обліку в ІТ СППР, які інваріантні щодо особливостей підприємства і будуть складовими методики формалізації інформації при проектуванні IT. Визначено особливості обліку даних аудиту передумови за період перевірки в підсистемі первинного обліку. Це дозволило визначити, що пряме відображення даних, підпорядковане передумові багатозначно, а зворотне однозначно, а також, що перевірка передумови не декомпозується в автоматичному режимі на рішення елементарних задач по кожному об'єкту обліку та операції. На підставі методики узагальнено-множинного відображення інформації виконана постановка двох видів задач автоматизованого аналізу даних елементарних задач за період перевірки в підсистемі аудиту передумови. Дані постановки задач інваріантні щодо особливостей підприємства і $є$ підставою для створення наступних елементів методики формалізації інформації в ІТ СППР.
\end{abstract}

Ключов і слов а: постановка задачі, автоматизований аналіз даних, інформаційна технологія, СППР аудиту, методика узагальнено-множинного відображення інформації, первинний облік.

\section{Вступ}

На даний час поточною науково-технічною проблемою інформаційних технологій фінансовоекономічної сфери є автоматизація аналізу великих обсягів даних фінансово-економічної інформації підприємств, що зберігаються і надходять в режимі онлайн в базах даних локальних та глобальних комп'ютерних систем 3 метою формування рекомендацій щодо прийняття рішень під час аудиту. Наприклад, ефективність IT-бізнесу у зниженні корупції обгрунтована в [1]. В [2] обговорюються теоретичні та практичні питання використання IT в аудиторській сфері. Визначено зміни, які вносить до методології аудиту його комплексна комп'ютеризація.

Застосування сучасних систем бухгалтерського обліку та управління на підприємстві, що інтегровані в глобальні, багаторівневі системи інформаційних комп'ютерних мереж, надає потенційні можливості обробки великих обсягів даних, які використовуються не в повному обсязі [3]. В [4] представлено архітектуру підсистем зовнішнього і внутрішнього аудиту системи Аудит 4.0, функціонування та експлуатація яких стикається 3 проблемою обробки великих обсягів даних. Також сьогодні в практичних i наукових джерелах, які вивчають проблеми та перспективи розвитку аудита розглядається можливість прийняття законодавчих актів, які дозволять використовувати аналітичні докази (зокрема суперечливості даних) отриманих при аналізі великих обсягів даних, як основи для судових рішень без документального вивчення первинних документів [5].

Говорячи про автоматизацію процедур аналізу, слід зазначити, що в літературі представлені методи виявлення шахрайства на основі застосування моделей нейронних (імовірнісних) мереж, логістичної регресії, дерев рішень, експертних оцінок, статистичні методи аналізу даних [6-9]. Застосування цих методів дозволяє аналізувати окремі показники або виявляти аномальні значення. Їх застосування дає ре- зультати, якщо виконуються певні умови, які залежать від характеристик показників, тобто вони не $\epsilon$ універсальними, що ускладнює їх використання при вирішенні задач автоматизації на всіх етапах аудиту. Це свідчить про те, що тематика дослідження, яка стосується проектування IT-аудиту є актуальною.

Аналіз літературних даних i постановка проблеми. При проектуванні IT-аудиту необхідно припускати можливість їх застосування до фінансово-економічних даних підприємств різних галузей, видів виробництва різної організаційної структури та IT обліку. Економіко-виробнича діяльність та IT підприємства утворюють складну соціально-економічну технічну систему. Ця система, як об'єкт аудиту, характеризується глобальною багаторівневою ієрархічною структурою гетерогенних, багатофакторних, багатофункціональних взаємозв'язків, взаємозалежностей i взаємодій іï підсистем, 3 ITконтролю, обліку, управління, ведення бізнесу, 3 іншими IT і системами в структурі інформаційної системи національної економіки. У той же час дані на кожному рівні мають мережеву структуру. Сучасна методологія прикладного системного аналізу не відповідає цим вимогам [10]. Тому є проблема розробки методологічних основ IT-аудиту.

В [11] обгрунтовується необхідність атрибутивної вибіркової перевірки документів навіть за умов повної автоматизації обліку на підставі статистичного підходу до формування аудиторської вибірки. Представлена методика атрибутивного вибіркового дослідження дозволяє визначити обсяг вибірки і верхню межу точності. Однак залишається відкритим питання про методику тестування по кожній групі документів і взаємопов'язаним групам документів (послідовних операцій). Також вказується, що в силу того, що господарські операції та первинні документи формуються за допомогою програм, тому помилки пов'язані з розрахунком сум практично виключені. У той же час тестування необхідно застосовувати з метою з'ясування чи мали дійсно місце факти господар- 
ської діяльності враховані в БД комп'ютерної програми обліку. Однак не виконана формальна постановка даного завдання, а також завдання виявлення ознак існування фактів господарської діяльності, які мали місце і не враховані в БД.

В [2] в розділі обгрунтування безпосереднього дослідження облікових записів, наведений перелік проблемних питань, пов'язаних з застосуванням вибіркового методу в аудиті [2, стор. 329]. Також пропонується використання закону Ф. Бенфорда «аномальних чисел» для безперервного статистичного дослідження рахунків і наводяться 4 умови и приклади практичного застосування. Перевірка цих умов вимагає додаткових програмних ресурсів, оскільки вона має застосовуватися до кожного показника і залишається незрозумілим, що робити, якщо ці умови не виконані.

Таким чином, ці методи аналізу дозволяють автоматизувати в IT аудиту лише окремі процедури аналізу (наприклад, формування вибірки) або проводити аналітичні процедури в особливих випадках [10]. Не враховуються взаємозв'язки між показниками взаємозалежних груп документів (записів) [2-5] і не $\epsilon$ універсальними для всіх показників, що ускладнює автоматизацію аналізу на їх основі. Тобто існує проблема повноти, універсальності та комплексності методики IT-аналізу.

В [5] визначено, що існуючі ліцензійне програмне забезпечення на ринку України дозволяє вирішувати наступні задачі: автоматизувати значну частину трудомістких процедур, планування и контролю витрат робочого часу на персоналу. Тим не менш, розглянуті IT-аудиту характеризуються наступними проблемами: відсутність взаємопов'язаного (за завданнями, рівнями) аналізу, зворотного зв'язку з його ефективністю та результативністю, оптимізації аналізу відповідно до цілей і обмежень, встановлених ОПР, а також діалог з ОПР на мові предметної області на етапі призначення завдання i тлумачення результатів аналізу.

Проектування IT СППР відповідно до методики узагальнено-множинного відображення інформації запропонованої в [12] вимагає створення методики формалізації інформації первинного обліку для автоматизованого вирішення завдань аудиту передумов П (С) БО. Перший етап створення методики постановка елементарних завдань при проектуванні підсистеми аудиту передумови виконаний в роботі [13]. В [13] виділені два види елементарних задач і виконана їх формальна постановка. Перша елементарна задача - визначення еквівалентних і нееквівалентний підмножин при відображенні характеристик взаємопов'язаних операцій, між якими існують відносини відповідності до об'єкту обліку. Друга елементарна задача - визначення еквівалентних i нееквівалентний підмножин при відображенні даних обліку об'єктів двох видів, для яких існують відносини відповідності до однієї операції.

Методика постановки елементарних задач проілюстрована на прикладі підсистеми аудиту передумови «Повнота» матеріальних витрат. Дані елементарні задачі утворюють набір задач по відношенню до всіх об'єктів обліку та операціями за період перевірки за всіма видами взаємопов'язаних об'єктів і операцій при обліку матеріальних витрат.

Мета статті: виконати формальну постановку завдань автоматизованого аналізу даних для набору елементарних задач підсистеми аудиту передумови за період перевірки інваріантну щодо особливостей підприємства і як складових методики формалізації інформації при проектуванні IT.

Для цього необхідно вирішити такі задачі:

1) визначити функціональні особливості обліку даних елементарних задач аудиту за період перевірки;

2) виконати формальну постановку задач автоматизованого аналізу даних елементарних задач за період перевірки.

В порядку спільності методика розглядається для підсистеми аудиту передумови «Повнота» даних первинного обліку економіко-виробничої (основний) діяльності підприємства так як в силу розмірності даних, видів взаємозв'язків між ними і кількості елементарних підсистем первинного обліку це найбільш загальна і трудомістка задача.

Для наочності і зв'язку з попередніми результатами автора [13] складові методики розглядаються на прикладі підсистеми аудиту передумови «Повнота» матеріальних витрат.

\section{Функціональні особливості обліку множин даних елементарних задач за період перевірки}

Множини даних елементарних задач аудиту утворюють значення характеристик об'єктів обліку та операцій та відношень відповідності між ними. Визначимо їх структуру в підсистемах первинного обліку. Значення характеристик об'єктів обліку кожного виду в первинних підсистемах накопичуються в хронологічному порядку в окремій підсистемі і утворюють множини даних первинного обліку об'єктів кожного виду:

$$
E_{S}=\left\{e_{S}\left(n_{s}, \text { data }\right), \text { data } \in T\right\}, s=\overline{1, S},
$$

де $E$ - множина даних об'єктів первинного обліку, $e$ - множина даних об'єкта первинного обліку, $s$ та $S$ - вид і кількість видів об'єктів обліку, $T$ - період обліку, $n$ - номер підсистеми обліку, data - дата створення підсистеми обліку.

Тоді множина даних первинного обліку об'єктів $E$ за період $T$ можна представити у вигляді об'єднання підмножин даних первинних обліку об'єктів кожного виду, які не перетинаються:

$$
E=\bigcup_{s=1}^{S} E_{s}, E_{S} \cap E_{g}=\varnothing, s \neq g .
$$

Значення характеристик операцій в підсистемах первинного обліку (ППУ) за період $T$, які знаходяться відносинах відповідності до елементів множин $E_{s-1}(T)$ та $E_{S}(T)$ утворюють множини даних первинного обліку етапів економіко-вироб- 
ничої діяльності (наприклад, здійснення матеріальних витрат):

$$
X_{s-1}^{s}=\left\{\begin{array}{c}
x_{s}\left(n_{s}, \text { data }\right):\left(x_{s} r^{-} e_{s-1}\right) \wedge \\
\wedge\left(x_{s} r^{+} e_{s}\right) \wedge(\text { data } \in T)
\end{array}\right\},
$$

де $X_{s-1}^{S}$ - множина даних операцій первинного обліку, які знаходяться відносинах відповідності до елементів множин $E_{s-1}$ і $E_{S}, T$ - період обліку, $x$ множина даних первинного обліку операції.

Тоді множина даних операцій $X$ за період $T$ можна представити у вигляді об'єднання непересічних підмножин даних операцій $X_{s-1}^{s}$ и $X_{s}^{s+1}$ по етапах економіко-виробничої діяльності:

$$
X=\bigcup_{s=0}^{S-1} X_{s}^{s+1}=\bigcup_{l=1}^{S} X_{l}, X_{l} \cap X_{m}=\varnothing, l \neq m .
$$

Для визначення структури відносин відповідності між елементами множин даних $E_{s}$ об'єктів обліку (1) і множин операцій $X_{s}^{s+1}$ (4) за період $T$, визначимо їх вид для одного об'єкта обліку. Виділимо наступні функціональні особливості системи обліку даних множин і відносин між ними:

$\Phi_{1}$ - ППУ с номером $n_{s}$ обліку операції $x_{s}\left(n_{s}\right)$, яка знаходиться в відношенні відповідності збільшення $r_{s}^{+}\left(n_{s}\right)$ к об'єкту обліку $e_{s}\left(n_{s}\right)$ єдина;

$\Phi_{2} \quad$ - ППУ операцій $x_{s+1}\left(n_{s+1}\right)$ $\left(x_{s+1}\left(n_{s+1}\right) \in X_{s}^{s+1}\left(n_{s}\right), X_{s}^{s+1}\left(n_{s}\right) \subset X_{s}^{s+1}\right)$,

які перебувають у відношенні відповідності $r_{s}^{-}\left(n_{s+1}\right)$ зменшення об'єкта обліку $e_{S}\left(n_{s}\right)$ в загальному випадку більше або дорівнює 1:

$$
\begin{aligned}
\forall e_{S}\left(n_{s}\right) & \in E\left(\exists ! n_{s} \in N_{s}: x_{s}\left(n_{s}\right) r_{s}^{+}\left(n_{s}\right) e_{s}\left(n_{s}\right)\right) \wedge \\
& \wedge\left(\begin{array}{l}
\exists x_{s+1}\left(n_{s+1}\right) \in X_{s}^{s+1}\left(n_{s}\right): \\
x_{s+1}\left(n_{s+1}\right) r_{s}^{-}\left(n_{s+1}\right) e_{s}\left(n_{s}\right)
\end{array}\right) .
\end{aligned}
$$

Отже, відносини відповідності між ППО а також між об'єктами обліку і операціями за період одно-багатозначні.

Формалізуємо співвідношення (5) у вигляді графа $G_{1}$ (рис. 1):

$$
\begin{gathered}
G_{1}\left(e_{s}\right)=\left(V_{1}\left(e_{s}\right), R_{1}\left(e_{s}\right)\right), \\
V_{1}\left(e_{s}\right)=\left(x_{s}, x_{s+1}^{1}, \ldots, x_{s+1}^{k}, e_{s}\right), \\
R_{1}\left(e_{s}\right)=\left(r_{s}^{+}, r_{s}^{-}\left(n_{s+1}^{1}\right), \ldots, r_{s}^{-}\left(n_{s+1}^{k}\right)\right), \\
e_{s}\left(n_{s}\right) \in E_{s} \quad s=\overline{1,4},
\end{gathered}
$$

де $G_{1}$ - граф відносин відповідності даних взаємопов'язаних операцій первинного обліку за період $T$ до даних об'єкта первинного обліку, $V_{1}$ - множина вершин графа $G_{1}, R_{1}$ - множина ребер графа $G_{1}$, $e$ - вершина, що характеризує дані об'єкта первинного обліку, $s$ - вид об'єкта обліку, $x$ - вершина, що характеризує дані первинного обліку операції, $k$ кількість операцій, $r^{+}$- ребро, що характеризує дані первинного обліку відносини відповідності операції до збільшення об'єкта обліку, $r^{-}$- ребро, що характеризує дані первинного обліку відносини відповідності операції до зменшення об'єкта обліку, $n$ - номер первинної підсистеми.

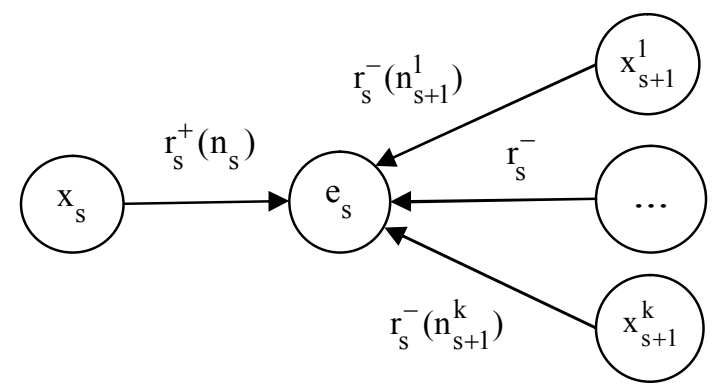

Рис. 1. Граф $G_{1}$ відносин відповідності даних взаємопов'язаних операцій первинного обліку за період $T$ до даних об'єкта первинного обліку

Дані первинного обліку відносин відповідностей взаємопов'язаних операцій виду $G_{1}$ до кожного об'єкту обліку за період породжують множини даних первинного обліку відносин відповідності:

$$
\begin{gathered}
R_{s}^{+}=\left\{r_{s}^{+}\left(n_{s}\right): \exists x \in X_{s-1}^{s}: x r_{s}^{+} e_{s}\left(n_{s}\right), n_{s} \in N_{s}\right\}, \\
s=\overline{1,4}, \\
R_{s+1}^{-}=\left\{r_{s}^{-}\left(n_{s+1}\right): \exists x \in X_{s}^{s+1}: x r_{s}^{-} e_{s}\left(n_{s}\right),\right. \\
\left.n_{s} \in N_{s}, n_{s+1} \in N_{s+1}\right\}, s=\overline{0,3} .
\end{gathered}
$$

В силу функціональної особливості системи обліку $\Phi_{2}$, для кожного об'єкта $e_{s}\left(n_{s}\right) \in E_{s}$ існує множина об'єктів $E_{s+1}\left(n_{s}\right) \subset E_{s+1}$, які перебувають у відношенні відповідності з даним об'єктом:

$$
\begin{gathered}
\forall e_{s}\left(n_{s}\right) \in E_{s} \exists e_{s+1}\left(n_{s+1}\right) \in E_{s+1}\left(n_{s}\right) \subset E_{s+1}: \\
\left(\left(x_{s+1}\left(n_{s+1}\right) r_{s}^{-}\left(n_{s+1}\right) e_{s}\left(n_{s}\right)\right) \wedge\right. \\
\left(x_{s+1}\left(n_{s+1}\right) r^{+}\left(n_{s+1}\right) e_{s+1}\left(n_{s+1}\right)\right) .
\end{gathered}
$$

Формалізуємо співвідношення (9) у вигляді графа $G_{2}$ (рис. 2):

$$
\begin{gathered}
G_{2}\left(e_{s}\right)=\left(V_{2}\left(e_{s}\right), R_{2}\left(e_{s}\right)\right), \\
V_{2}\left(e_{s}\right)=\left(e_{s}, x_{s+1}^{1}, \ldots, x_{s+1}^{k}, e_{s+1}^{1}, \ldots, e_{s+1}^{k}\right), \\
R_{2}\left(e_{s}\right)=\left(r_{s}^{-}\left(n_{s+1}^{1}\right), \ldots, r_{s}^{-}\left(n_{s+1}^{k}\right),\right. \\
\left.r_{s+1}^{+}\left(n_{s+1}^{1}\right), \ldots, r_{s+1}^{+}\left(n_{s+1}^{k}\right)\right), \overline{e_{s}}\left(n_{s}\right) \in E_{s}, s=\overline{0,3},
\end{gathered}
$$

де $G_{2}$ - граф відносин відповідності даних взаємопов'язаних об'єктів первинного обліку за період $T$ 
до операції, $V_{2}$ - множина вершин графа $G_{2}, R_{2}$ множина ребер графа $G_{2}$.

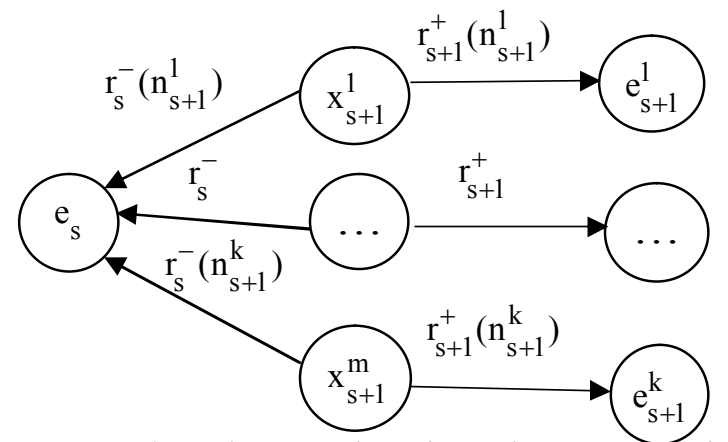

Рис. 2. Граф $G_{2}$ відносин відповідності даних операцій первинного обліку за період $T$ к об'єкту обліку.

Відносини відповідності формалізовані в графі $G_{1}$ породжують відображення множин значень характеристик взаємопов'язаних операцій $X_{s-1}^{s}$ і $X_{S}^{s+1}$ в ППУ за період $T$, яке мав би підпорядковуватися правилам передумови.

Значення характеристик взаємопов'язаних операцій множин $X_{s-1}^{s}$ і $X_{s}^{s+1}$ в ППУ враховуються в хронологічному порядку за період $T$ у відповідних підсистемах. При цьому дані операцій $x_{s} \in X_{s-1}^{s}$ та $x_{s+1} \in X_{s}^{s+1}$, які перебувають у відношенні відповідності виду $G_{1}$ до одного об'єкту обліку.

Відносини відповідності формалізовані в графі $G_{2}$ породжують відображення множин значень характеристик взаємопов'язаних об'єктів обліку $E_{s}$ i $E_{S+1}$ в ППУ за період $T$, яке мав би підпорядковуватися правилам передумови. Отже, дані два види відображення множин підлягають перевірці в підсистемі аудиту передумови і для них необхідно виконати формальну постановку задачі.

Далі виділимо третю функціональну особливість $\Phi_{3}$ системи обліку множин даних елементарних задач. Значення характеристик взаємопов'язаних об'єктів обліку $E_{s}$ і $E_{s+1}$ в ППО враховуються в хронологічному порядку за період $T$ у відповідних підсистемах. При цьому дані об'єктів обліку $e_{s} \in E_{s}$ и $e_{s+1} \in E_{s+1}$, які перебувають у відношенні відповідності виду $G_{2}$ до однієї операції НЕ узагальнюються в окремій підсистемі в автоматичному режимі. Тому перевірка передумови не декомпозується в автоматичному режимі на рішення елементарних завдань по кожному об'єкту обліку та операції. Тому виконаємо постановку автоматизованого аналізу для задач аудиту передумови для множин елементарних завдань за період $T$.

\section{Постановка задач \\ автоматизованого аналізу в підсистемі аудиту передумови}

На підставі виконаної вище формалізації множин перевірки (1) і (3) і двох видів взаємозв'язків між ними представлених у вигляді графів $G_{1}$ i $G_{2}$, виконаємо формальну постановку двох видів локальних задач аудиту передумови.

Перша локальна задача - визначення еквівалентних і нееквівалентний підмножин при відображенні даних множин операцій $X_{s-1}^{s}$ і $X_{s}^{s+1}$ в первинних підсистемах, між якими існують відносини відповідності виду $G_{1}$ до об'єктів обліку множини $E_{s}$ за період перевірки $T$.

Друга локальна задача - визначення еквівалентних і нееквівалентних підмножин при відображенні даних обліку множин об'єктів $E_{S}$ і $E_{s+1}$ двох видів в первинних підсистемах для яких існують відносини відповідності виду $G_{2}$ до операцій множини $X_{S}^{s+1}$ за період перевірки $T$.

Для виділених завдань необхідно сформувати методики їх вирішення. Методика рішення першої локальної задачі буде, наприклад, реалізуватися в наступних підсистемах аудиту даних матеріальних витрат: «Розрахунки $з$ постачальниками», «Запаси», «Виробництво», «Готова продукція». Методика рішення другої локальної задачі буде, наприклад, реалізуватися в підсистемах аудиту взаємозв'язків між перерахованими підсистемами обліку матеріальних витрат. Для вирішення виділених локальних задач формуються відповідні підсистеми. У СППР аудиту множина даних, що перевіряються може бути визначено за результатами аудиту на верхніх рівнях, або задано ЛПР на нижньому.

\section{Висновки}

1. Визначено особливості автоматичного обліку характеристик елементів предметної області та взаємозв'язків між ними в підсистемі первинного обліку які інваріантні щодо особливостей підприємства. Це дозволило визначити, що пряме відображення даних підсистемах первинного обліку багатозначно, а зворотне однозначно, а також, що перевірка передумови не декомпозується в автоматичному режимі на рішення елементарних задач по кожному об'єкту обліку та операції.

2. На підставі методики узагальнено-множинного відображення інформації виконана постановка задач автоматизованого аналізу даних в підсистемі аудиту передумови, які інваріантні щодо особливостей підприємства. Це дозволяє перейти до наступних етапів створення методики формалізації інформації в ІТ СППР аудиту

\section{СПИСОК ЛІТЕРАТУРИ}

1. Xinli Hu. Effectiveness of information technology in reducing corruption in China / Xinli, Hu // Electronic Library, 2015 Vol. 33. - Issue 1. - P. 52-64, doi: https://doi.org/10,1108 / el-11-2012-0148.

2. Ивахненков С. В. Информационные технологии аудита и внутрихозяйственного контроля в контексте мировой интеграции: монография / С. В. Ивахненков - Житомир: ЧП «Рута», 2010. - 432 с. 
3. Kirkos E. Data mining techniques for the detection of fraudulent financial statement / E. Kirkos, C. Spathis, Y. Manolopoulos // Expert Syst. Appl., 2007- Vol. 32 Issue 4. - p. 995-1003.9, doi: https://doi.org/10.1016/j.eswa.2006.02.016.

4. Dai J, Vasarhelyi M. A. Imagineering Audit 4.0 / J. Dai, M. A. Vasarhelyi. // Journal of Emerging Technologies in Accounting, 2016 - № 13(1). - P. 1-15.

5. Яремко С.А., Коваленко В.В. Дослідження проблем впровадження сучасних інформаційних систем аудиту в контрольно-ревізійній діяльності / С.А. Яремко, В.В. Коваленко // Комп'ютерно-інтегровані технології освіта наука виробництво - Луцьк, 2014. - № 14 - С. 179-182.

6. Jarrod West. Intelligent Financial Fraud Detection Practices: a comprehensive review / West Jarrod, M Bhattacharya and R Islam // Computers \& Security, 2016. - Vol. 57. - P. 47-66. doi: https://doi.org/10.1007 / 978-3-319-23802-9_16

7. Chi-Chen Lin. Detecting the financial statement fraud: The analysis of the differences between data mining techniques and experts' judgments / Lin Chi-Chen, Chiu An-An, Yan Huang Shaio, C. Yen. David // Knowledge-Based Systems, 2015. - № 89. - P. 459-470, doi: 10.1016 /j.knosys.2015.08.011.

8. Mohiuddin Ahmeda. A survey of anomaly detection techniques in financial domain / A Mohiuddin, N Mahmooda Abdun, Md Rafiqul Islam // Future Generation Computer Systems, 2016. - № 55. - P. 278-288. doi: https://doi.org/10.1016/j.future.2015.01.001

9. Бююль A. SPSS: Искусство обработки информации. Анализ статистических данных и восстановление скрытых закономерностей / А. Бююль, П. Цёфель; пер. с нем. - Спб.: ДиаСофтЮП, 2005. - 608 с.

10. Згуровський М. 3. «Системний аналіз: Методологія. Проблеми. Приложения». Монографія 2-е видання, перероблене та доповнене / М. З. Згуровський, Н. Д. Панкратова - Київ, вид-во «Наукова думка», 2016. - 726 с.

11. Андренко Е. А. Методика атрибутивного выборочного исследования в аудите / Е. А. Андренко, С. М. Мордовцев // Бизнес Информ, 2013. - № 2. - С. 200-203.

12. Нескородева, Т. В. Правила и составные части методики обобщенно-множественного отображения информации в подсистеме аналитического учета СППР аудита верхнего уровня/ Т. В. Нескородева // Вісник НТУ «ХПІ». Серія: Системний аналіз, управління та інформаційні технології. - Харків : НТУ «ХПІ», 2017. - № 55 (1276). - С. 31-38.

13. Нескородєва, Т. В. Постановка елементарних задач аудиту передумови положень бухгалтерського обліку в інформаційній технології системи підтримки прийняття рішень / Т. В. Нескородєва // Сучасні інформаційні системи. 2019. Т. 3, № 1 - C. 48-53. doi: https://doi.org/10.20998/2522-9052.2019.1.08.

Рецензент: д-р техн. наук, доц. А. А. Коваленко, Харківський національний університет радіоелектроніки, Харків Received (Надійшла) 19.03.2019 Accepted for publication (Прийнята до друку) 15.05.2019

\section{Постановка задач автоматизированного анализа данных в подсистеме аудита предпосылки информационной технологии системы поддержки принятия решений}

\section{Т. В. Нескородева}

Цель статьи. Выполнить постановку задач аудита автоматизированного анализа данных в подсистеме аудита предпосылки Положений (стандартов) бухгалтерского учета в ИТ СППР, которые инвариантны относительно особенностей предприятия и будут составляющими методики формализации информации при проектировании ИТ. Определено, что существует проблема универсальности инструментария автоматизированного анализа, а также полноты, и комплексности методик проектирования ИТ аудита. Определены особенности учета данных аудита предпосылки за период проверки в подсистеме первичного учета. Это позволило определить, что прямое отображение данных, подчиненных предпосылке многозначно, а обратное однозначно, а также, что проверка предпосылки не декомпозируется в автоматическом режиме на решение элементарных задач по каждому объекту учета и операции. На основании методики обобщенно-множественного отображения информации выполнена постановка двух видов задач автоматизированного анализа данных элементарных подзадач за период проверки в подсистеме аудита предпосылки. Данные постановки задач инвариантных относительно особенностей предприятия и являются основанием для создания следующих элементов методики формализации информации в ИТ СППР.

Ключевые слова: постановка задачи, автоматизированный анализ данных, информационная технология, СППР аудита, методика обобщенно-множественного отображения информации, первичный учет

\section{Setting the tasks of automated data analysis in the precondition audit subsystem information technology of the decision support system}

\section{T. Neskorodieva}

The purpose of the article. Perform the formulation of the audit tasks of automated data analysis in the audit subsystem of the precondition of the Regulations (standards) of accounting in IT DSS, which are invariant with respect to the features of the enterprise and will be part of the methodology for formalizing information in IT design. It was determined that there is a problem of universality of automated analysis tools, as well as the completeness and complexity of IT audit design techniques. The specifics of accounting for audit data for the prerequisite for the period of verification in the primary accounting subsystem are determined. This made it possible to determine that direct mapping of data subordinate to a premise is multivalued, and the opposite is unique, and that verification of a premise is not automatically decomposed into solving elementary problems for each accounting object and operation. Based on the method of generalized-multiple display of information, two types of tasks for automated data analysis of elementary subtasks for the period of checking in the audit subsystem of the premise were set. The data of setting tasks invariant with respect to the specific features of the enterprise are the basis for creating the following elements of the method of formalizing information in IT DSS.

Keywords: problem statement, automated data analysis, information technology, DSS audit, the method of generalizedmultiple display of information, primary accounting. 